\title{
Unique and shared roles of the posterior parietal and dorsolateral prefrontal cortex in cognitive functions
}

\author{
Fumi Katsuki and Christos Constantinidis* \\ Department of Neurobiology and Anatomy, Wake Forest University School of Medicine, Winston-Salem, NC, USA
}

\section{Edited by:}

David J. Bucci, Dartmouth College, USA

\section{Reviewed by:}

Bruno B. Averbeck, National Institute of Mental Health, USA

Emmanuel Procyk, Institut Nationale de la Santé et de la Recherche

Médicale, France

\section{*Correspondence:}

Christos Constantinidis, Department of Neurobiology and Anatomy, Wake

Forest University School of

Medicine, Medical Center Blvd,

Winston-Salem, NC 27157, USA.

e-mail:cconstan@wfubmc.edu
The dorsolateral prefrontal cortex (PFC) and posterior parietal cortex (PPC) are two parts of a broader brain network involved in the control of cognitive functions such as working-memory, spatial attention, and decision-making. The two areas share many functional properties and exhibit similar patterns of activation during the execution of mental operations. However, neurophysiological experiments in non-human primates have also documented subtle differences, revealing functional specialization within the fronto-parietal network. These differences include the ability of the PFC to influence memory performance, attention allocation, and motor responses to a greater extent, and to resist interference by distracting stimuli. In recent years, distinct cellular and anatomical differences have been identified, offering insights into how functional specialization is achieved. This article reviews the common functions and functional differences between the PFC and PPC, and their underlying mechanisms.

Keywords: monkey, neurophysiology, neuron, principal sulcus, intraparietal sulcus, persistent activity, attention

\section{INTRODUCTION}

The prefrontal cortex (PFC) has traditionally been viewed as the brain area associated with higher cognitive operations and executive function (Goldman-Rakic, 1987; Miller and Cohen, 2001). Neurophysiological experiments in non-human primates have been instrumental in uncovering the nature of prefrontal involvement in mental processes by revealing that activity of prefrontal cortical neurons constitutes neural correlates of cognitive functions. Correlates of a wide range of functions have now been identified in the PFC, including working-memory (Fuster and Alexander, 1971; Funahashi et al., 1989), perceptual decisions (Kim and Shadlen, 1999; Barraclough et al., 2004), abstract rules (White and Wise, 1999; Wallis et al., 2001), reward expectation (Leon and Shadlen, 1999), associative learning (Asaad et al., 2000), categories (Freedman et al., 2001; Shima et al., 2007), numerical quantities (Nieder et al., 2002), and planning of sequences of actions (Averbeck et al., 2002; Hoshi and Tanji, 2004; Inoue and Mikami, 2006; Berdyyeva and Olson, 2010).

Although these studies confirm the involvement of the PFC in cognitive functions, in recent years it has also been recognized that other cortical areas manifest equivalent neural correlates during cognitive operations. The posterior parietal cortex (PPC), in particular, is tightly interconnected with the PFC and has been shown to exhibit similar properties in a wide range of paradigms tested in both areas. Neuronal responses in posterior parietal areas (such as areas LIP and 7a) are also known to be activated during spatial working-memory (Gnadt and Andersen, 1988; Quintana and Fuster, 1992; Constantinidis and Steinmetz, 1996; Chafee and Goldman-Rakic, 1998) and to represent neural correlates of decision-making (Shadlen and Newsome, 1996; Yang and Shadlen, 2007), planning (Crowe et al., 2005), reward expectation (Platt and Glimcher, 1999; Sugrue et al., 2004), rules
(Stoet and Snyder, 2004), categories (Freedman and Assad, 2006; Swaminathan and Freedman, 2012), associations (Fitzgerald et al., 2011), and numerical quantities (Nieder and Miller, 2004; Roitman et al., 2007). It is clear, therefore, that representation of neural correlates of higher cognitive functions is not the exclusive domain of the PFC and it has become more difficult to identify neurophysiological differences than similarities between the two areas. Elucidating the shared and unique roles of the prefrontal and parietal cortex will provide important insights into the neural mechanisms of higher cognitive functions. In this review, we will focus on the functional specialization of the PFC and PPC in cognitive processes as revealed by neurophysiological experiments in non-human primates, with an emphasis on visual processing.

\section{ANATOMICAL ORGANIZATION}

The primate PFC is subdivided into a medial, lateral, and orbital aspect. Here we will focus on the lateral PFC (colored region in Figures 1A,B), and the dorsal subdivision of the lateral PFC in particular (the dorsolateral PFC). Two alternative nomenclatures are widely used in the literature. We will adopt the nomenclature of Preuss and Goldman-Rakic (1991) and focus on areas 46 and $8 \mathrm{a}$, including the frontal eye fields (FEF), a part of area $8 \mathrm{a}$ extending in the anterior bank of the arcuate sulcus (Figure 1A). In the Petrides and Pandya (1994) nomenclature, the region we will be reviewing corresponds to areas $9 / 46$ and $8 \mathrm{~A}$.

The primate PPC also consists of several cortical areas (colored region in Figures $\mathbf{1 C}, \mathbf{D}$ ). This review will focus on the inferior lobule (posterior to the intraparietal sulcus) and particularly on the lateral intraparietal area (LIP) and area 7a (Figure 1C). In the alternative nomenclature of Pandya and Seltzer (1982), this region includes areas PG, Opt, and POa (Figure 1D). 
A

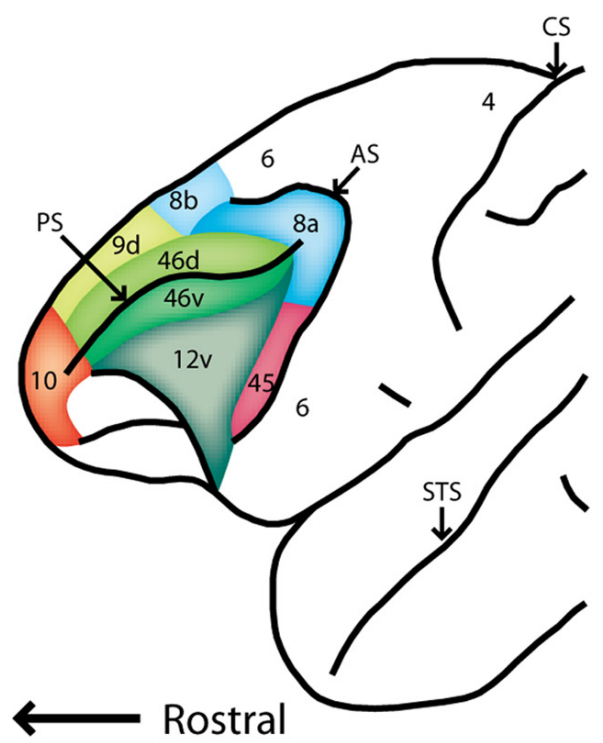

C
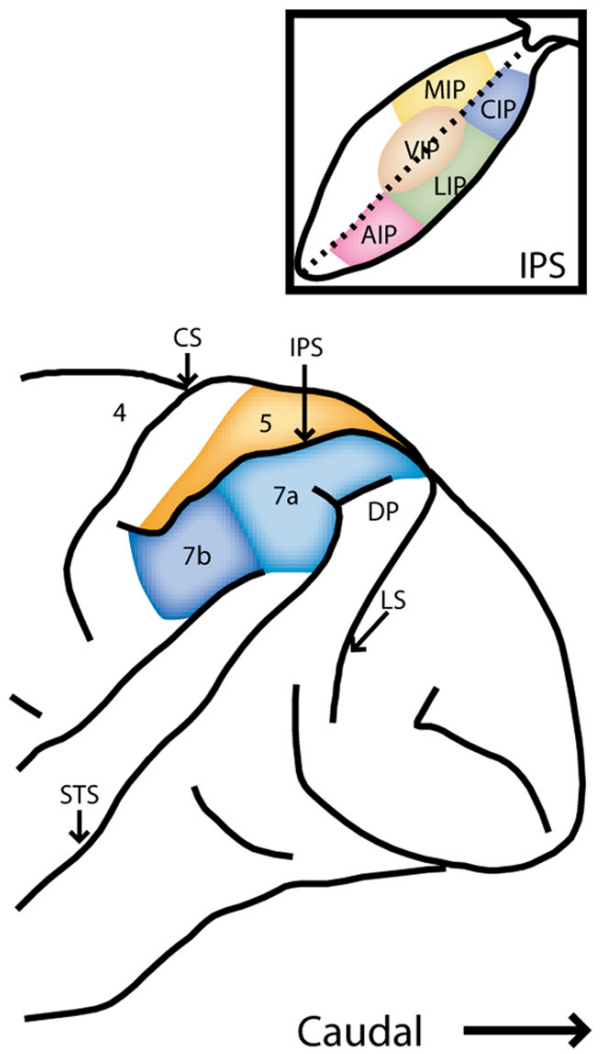

FIGURE 1 | Schematic diagrams of the lateral surface the macaque monkey. (A) Anterior half of monkey brain including the prefrontal cortex, adapted after Preuss and Goldman-Rakic [Preuss and Goldman-Rakic (1991)]. (B) Alternative map of prefrontal cortical areas, based on Petrides and Pandya [Petrides and Pandya (1994)]. (C) Posterior half of the monkey brain including the posterior parietal cortex. Inset depicts an unfolded view of the intraparietal sulcus Rawley and Constantinidis (2009).
B

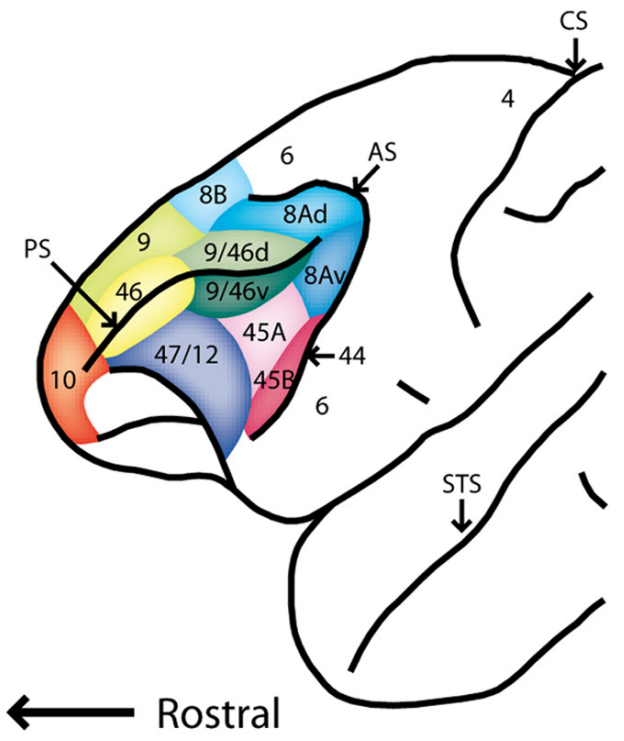

D
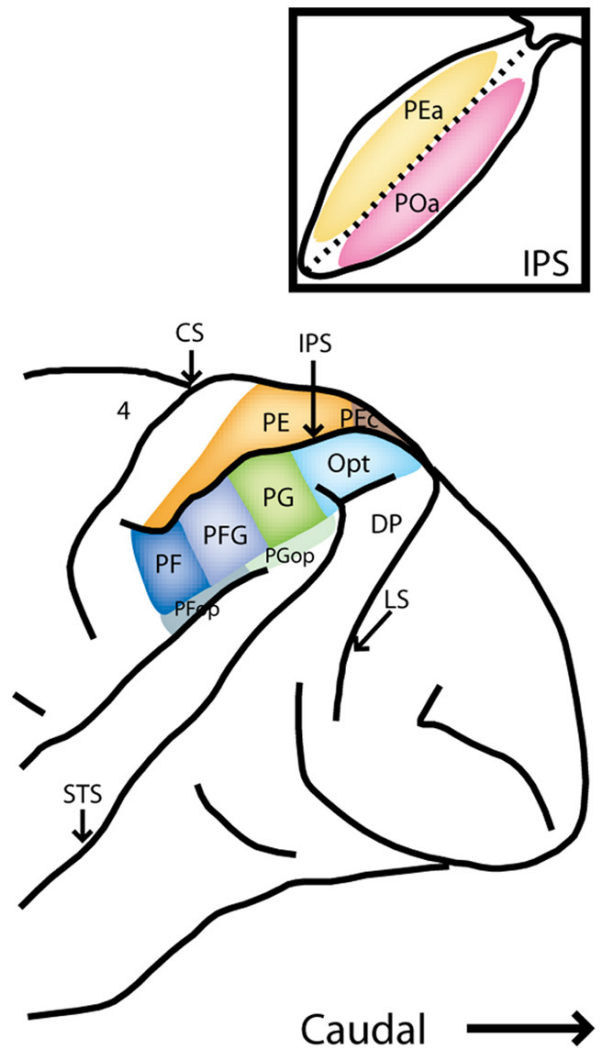

(D) Map of the posterior parietal cortex based on Pandya and Seltzer [Pandya and Seltzer (1982)]. Abbreviations: AIP, anterior intraparietal area; AS, arcuate sulcus; CIP, caudal intraparietal area; CS, central sulcus; DP, dorsal prelunate area; IPS, intraparietal sulcus; LIP, lateral intraparietal area; LS, lunate sulcus; MIP, medial intraparietal area;

PS, principle sulcus; STS, superior temporal sulcus; VIP, ventral intraparietal area. 


\section{CORTICAL PATHWAYS}

The image of the external world enters the eyes in the form of a continuous stream of light where it is transformed to action potentials in the retina, then transmitted to the lateral geniculate nucleus (LGN) of the thalamus and subsequently relayed to the primary visual cortex. Several dozen visual cortical areas have been identified beyond the striate cortex, organized in a hierarchical fashion (Felleman and van Essen, 1991; van Essen et al., 1992). Two broad pathways with fairly distinct anatomical organization and functional properties are generally referred to as the ventral and dorsal visual streams (Macko et al., 1982; Ungerleider and Mishkin, 1982; Ungerleider and Haxby, 1994). Initially identified based on monkey lesion studies, the ventral stream is traditionally considered as the "what" pathway dealing with representation of stimulus features (such as color and shape); the dorsal stream is described as the "where" pathway and processes spatial aspects of visual information (such as location and direction of motion). Both streams are organized hierarchically with patterns of connections following a stereotypical organization: layer 4 of a cortical area receives input from a subordinate cortical area, transforms the input in layers 2 and 3, and transmits the output to layer 4 of the cortical area to the next stage of the hierarchy (Hubel and Wiesel, 1962, 1965; Douglas and Martin, 2004, 2007). Convergence of inputs at each stage of the cortical hierarchy leads to neurons with progressively larger receptive fields and more complex functional properties. Feedback connections from higher into lower areas follow the opposite pattern: axons originating from layer 5 of the higher area terminate in layers 2 and 3 of the lower one (Felleman and van Essen, 1991; Douglas and Martin, 2004, 2007). In this scheme, the PPC represents the highest stages of the dorsal visual pathway, with area 7 a situated at the top level of the hierarchy (Felleman and van Essen, 1991). The PPC in turn projects to the dorsolateral PFC, however, the pattern of axonal termination is not indicative of a clearly hierarchical relationship. The PFC is recognized as a higher order area, yet connections between the two areas are parallel, originating and terminating in the same layers, rather than strictly serial (Barbas and Pandya, 1989; Cavada and Goldman-Rakic, 1989b; Felleman and van Essen, 1991). The relationship of anatomical connections between the two areas, therefore, offers no obvious insight into their relative functional specialization.

\section{INTER-AREAL CONNECTIONS}

In addition to dorsal visual stream inputs, the PPC is reciprocally connected with a number of cortical association areas involved in visuo-spatial processing, including the superior temporal, cingulate and parahippocampal cortex, as well as various subcortical structures, including the basal ganglia, pulvinar nucleus of the thalamus, and superior colliculus (Schwartz and Goldman-Rakic, 1984; Selemon and Goldman-Rakic, 1988; Cavada and GoldmanRakic, 1989a,b). Area LIP, in particular, has direct projections to and from extrastriate visual areas, and other cortical and subcortical areas involved in saccadic eye movements; these include the FEF, basal ganglia, and the superior colliculus, as well as other parietal areas (Asanuma et al., 1985; Lynch et al., 1985; Andersen et al., 1990; Blatt et al., 1990; Stanton et al., 1995). Area $7 \mathrm{a}$ is connected with visual cortical areas, including the medial superior temporal area (MST), the parieto-occipital area (PO), and LIP. It is also connected with other cortical association and limbic areas, including area 46 of the PFC, parahippocampal gyrus, and posterior cingulate cortex (Lynch et al., 1985; Selemon and Goldman-Rakic, 1988; Blatt et al., 1990; Rockland and van Hoesen, 1999).

The dorsolateral PFC (areas 8a and 46) processes visuo-spatial information by receiving a direct and robust input from posterior parietal areas 7a and LIP (Selemon and Goldman-Rakic, 1988; Cavada and Goldman-Rakic, 1989b). Area 46 shares many common efferent targets with the PPC, for example the supplementary motor cortex, premotor cortex, superior temporal cortex, cingulate cortex, limbic structures, basal ganglia, thalamus, and the superior colliculus (Selemon and Goldman-Rakic, 1988; Jouve et al., 1998). Area 8a (which includes the FEF) receives visual inputs not only from the PPC but also directly from most extrastriate areas of both dorsal and ventral visual pathways, and the superior colliculus via the thalamus (Huerta et al., 1986; Lynch et al., 1994; Jouve et al., 1998; Sommer and Wurtz, 2002; Ungerleider et al., 2008). Such direct connections with many visual areas allow the FEF to receive diverse and rapid visual input, positioning the area for efficient target selection and gaze shift through effector areas such as the basal ganglia and superior colliculus (Segraves and Goldberg, 1987; Sommer and Wurtz, 1998; Schall, 2002).

\section{FUNCTIONAL ACTIVATION AND SPECIALIZATION}

Considering the robust connectivity linking the dorsolateral PFC and PPC and their concurrent activation during a range of cognitive functions, the two brain areas are often viewed as part of a functional unit, the fronto-parietal network (Bisley and Goldberg, 2010). At the same time, a number of functional properties that differentiate the two areas have been discovered or proposed. These can be divided into three broad categories. First, the PFC can be viewed as closer to motor effectors in the cortical circuit generating and executing eye and limb movements. For example, low level $(<50 \mu \mathrm{A})$ microstimulation of the FEF generates saccades (Bruce et al., 1985), while a greater current amplitude is necessary in area LIP for the generating eye movements, which also appear with longer latency (Shibutani et al., 1984). Conversely, motor plans for limb movements have been shown to appear earlier in the parietal lobe (the Parietal Reach Region) than the frontal lobe (Snyder et al., 1997; Cui and Andersen, 2007). In this sense, the fundamental difference between the two areas lies not in the representation of cognitive processes, but in the generation of motor plans dictated by the cognitive factors represented in neuronal activity in both areas. A second view posits that the PFC, due to its intrinsic organization which places parietal and temporal inputs in relative proximity to each other, has the capacity to integrate spatial and feature information for the needs of complex cognitive tasks (Rao et al., 1997; Rainer et al., 1998a). Therefore, the dorsolateral and ventrolateral subdivisions of the PFC themselves differ not so much in the nature of the information that they represent, but rather in terms of processes such as learning and maintaining different types of associations and rules. Correspondingly the dorsolateral PFC may have the ability to represent a wider range of information than the PPC. 
A third category of potential functional differences has to do with further processing of information transmitted to PFC from the PPC, based on task demands, rules, or context. The ability of prefrontal neurons to resist the interference of distractors during working-memory is one such property (Constantinidis and Procyk, 2004). In the following sections, we review the properties of dorsolateral PFC and PPC in a series of cognitive functions that are unique or distinct between the two areas, and consider their functional implications. We should make clear that the review of studies in the following sections labeled "attention" and "working-memory" is somewhat arbitrary; behavioral tasks routinely require interplay of these factors and there is still debate about the fractionation of neuronal activity to these processes (Lebedev et al., 2004; Cisek and Kalaska, 2010; Gottlieb and Balan, 2010). We finally discuss the anatomical and cellular substrates that may mediate these differences.

\section{ATTENTION}

Attention is an essential cognitive process for selecting certain information in the environment to be processed in more detail, while filtering stimuli of less importance for the contingencies of the moment (Carrasco, 2011). Two distinct attentional systems have been identified: bottom-up attention, an externally evoked process in which information of a stimulus appearing in the environment is processed relatively automatically; and topdown attention, an internally evoked process in which stimuli are searched according to voluntarily selected features or locations (Itti and Koch, 2001; Corbetta and Shulman, 2002; Connor et al., 2004). Early human psychophysical studies revealed that stimuli that stand out by virtue of their relative saliency against their background attract attention and are able to be identified in parallel, without requiring search of every element in a display (Treisman and Gelade, 1980; Duncan and Humphreys, 1989). In contrast, stimuli that are not uniquely salient require volitional guidance of attention and serial inspection of elements in the display before they can be identified as targets of search (Wolfe and Horowitz, 2004). Both bottom-up and topdown factors interact for the guidance of attention in everyday experience (Wolfe, 2010). Models created to account for these psychophysical findings led to the proposal that visual features are processed into separate "feature maps" based on bottom-up activation that relies on the physical uniqueness of the stimulus in the field, and top-down activation that depends on the relevance of the stimulus to the task during visual search (Wolfe, 1994). The feature maps are then integrated into one "saliency map" (or "priority map" to denote the combined effect of bottom-up and top-down influences), according to which attention can be directed to the locus with highest activation in the map (Koch and Ullman, 1985). The existence of neural correlates of these saliency maps was only speculated at the time the concept was proposed, but distinct brain activation in response to salient stimuli has since been identified (Constantinidis, 2006). If anything, saliency maps now appear to be simultaneously present in multiple brain areas, including the PPC (Gottlieb et al., 1998; Constantinidis and Steinmetz, 2001), the PFC (Schall and Hanes, 1993; Thompson et al., 1996), and subcortical structures such as the superior colliculus
(McPeek and Keller, 2002) and substantia nigra (Basso and Wurtz, 2002). In the following paragraphs, we discuss the relative roles of dorsolateral PFC and PPC in bottom-up and top-down attention.

During search, neurons in the dorsolateral PFC preferentially represent salient stimuli while responses to distractors in the presence of salient stimuli are greatly suppressed (Figure 2 ). In particular, a series of studies in the FEF have revealed that neurons represent salient stimuli that stand out in terms of color or shape (Schall and Hanes, 1993; Schall et al., 1995; Thompson et al., 1996; Sato et al., 2003). The results indicate that the PFC maintains a map of visual saliency (Schall and Thompson, 1999). Indeed, microstimulation of the FEF, below the threshold of saccade generation can improve performance in attention tasks and increase the activity of single neurons in extrastriate visual areas (Moore and Fallah, 2001; Moore and Armstrong, 2003).

Neurons in areas 7a and LIP of the PPC exhibit similar patterns of responses as dorsolateral prefrontal neurons (Constantinidis and Steinmetz, 2001; Ipata et al., 2006; Thomas and Pare, 2007; Premereur et al., 2011). These preferential responses include activity driven purely by visual saliency and are present even in subjects not trained to perform a search task (Constantinidis and Steinmetz, 2005; Arcizet et al., 2011). Similarly, posterior parietal neurons represent preferentially visual stimuli rendered salient by being presented after background stimuli had already been visible (Gottlieb et al., 1998; Kusunoki et al., 2000). Therefore, activity across the PPC can also represent the location of salient stimuli and serve as a saliency or priority map (Bisley and Goldberg, 2010). Microstimulation of LIP can also bias selection of visual targets (Mirpour et al., 2010).

Functional differences between the two brain regions have been suggested in terms of the time course of selective representation of the salient stimulus (Figure 2). By some accounts, the PPC represents salient stimuli with shorter latencies, suggesting that this area provides the primary representation of visual saliency,

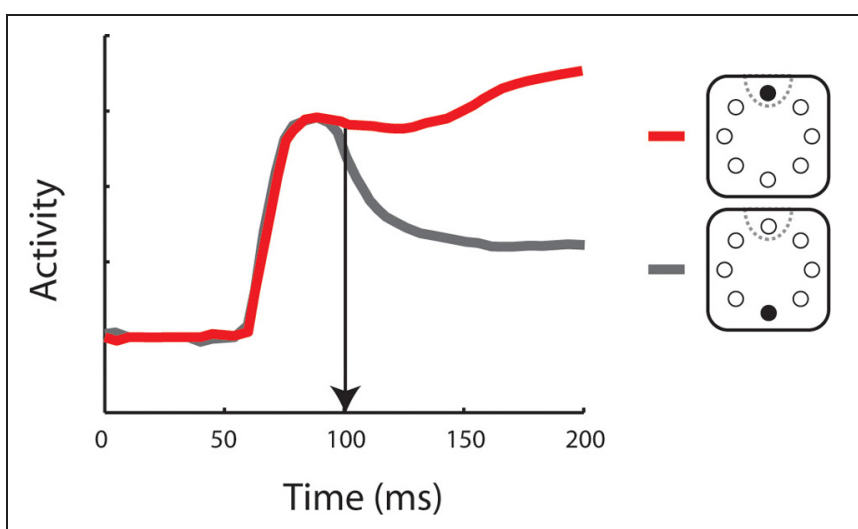

FIGURE 2 | Neuronal activity representing a salient stimulus.

Schematic illustration of a post-stimulus time histogram representing neuronal responses to two stimulus conditions. Insets depict the salient stimulus appearance in (red) or out (gray) of the neuron's receptive field (dotted line). Vertical arrow indicates the time of neuronal target discrimination. The diagram was constructed based on the results of Thompson and colleagues [Thompson et al. (1997)]. 
which is then transmitted to the dorsolateral PFC in a serial manner (Buschman and Miller, 2007). This finding remains controversial (Schall et al., 2007) as other studies have uncovered comparable time courses of activation in the FEF and PPC, employing essentially identical stimuli and analysis methods (Thompson et al., 1996; Thomas and Pare, 2007). It is also notable that the task used in the Buschman and Miller study did not rely entirely on a bottom-up process: a cue was presented to subjects in advance to the target presentation which could also involve top-down process. In any case, prefrontal activation appears to be essential for the completion of bottom-up tasks. Muscimol inactivation of the dorsolateral PFC has been reported to lead to deficits in visual search of a pop-out stimulus (Iba and Sawaguchi, 2003; Wardak et al., 2006). In summary, it is clear that both the PPC and dorsolateral PFC represent bottom-up visual saliency, although their relative role in the guidance of bottom-up attention remains a matter of debate.

In terms of top-down attention, neurons in the PPC show dramatic modulation to stimuli that a subject selects or is cued to attend to, compared to unattended stimuli (Robinson et al., 1978; Yin and Mountcastle, 1978; Bushnell et al., 1981; Toth and Assad, 2002; Bisley and Goldberg, 2003). Interestingly, parietal responses generally decrease when stimuli appear at locations that are already attended, leading to the hypothesis that the PPC plays a crucial role in the re-orienting of attention to a new stimulus of interest (Steinmetz et al., 1994; Steinmetz and Constantinidis, 1995). A causal role of the PPC in orienting attention has been revealed by chemical inactivation experiments; both eye movements and covert attention is impaired under muscimol injections (Wardak et al., 2002, 2004; Liu et al., 2010). Conversely, electrical microstimulation induces covert shifts of attention (Cutrell and Marrocco, 2002).

Responses of dorsolateral prefrontal neurons in top-down attention are similar in many respects. Prefrontal neurons preferentially represent attended over unattended stimuli (Rainer et al., 1998b; Lebedev et al., 2004). Microstimulation of the FEF has shown behavioral enhancement in tasks that require spatial attention and increase in firing rate in visual cortical areas, providing direct evidence of attentional control by the PFC (Moore and Fallah, 2001, 2004; Moore and Armstrong, 2003). On the other hand, reversible inactivation of the FEF through muscimol injection results in attentional deficits (Wardak et al., 2006).

Comparing the functional properties of the dorsolateral PFC and PPC in top-down attention reveals few differences. The PPC has been reported to represent targets of visual search defined by top-down factors later than the dorsolateral PFC (Buschman and Miller, 2007). This finding suggests that top-down signals originate in the PFC, and are only later represented in parietal activity. Comparison of inactivation effects of the FEF and area LIP also reveal distinct patterns of errors (Wardak et al., 2004, 2006). Specifically, prefrontal inactivation affects psychophysical performance in a search task both for difficult (conjunction) conditions and easy (feature detection) conditions. On the other hand, parietal inactivation selectively impairs the hardest types of search. The results suggest subtle but distinct roles of the PFC and parietal cortex in the guidance of attention.

\section{WORKING-MEMORY}

Working-memory is the ability to flexibly retain and manipulate information in mind, according to current needs (Baddeley, 2003). It is a fundamental component of higher cognitive functions including language, reasoning, planning, and decision-making (Curtis and Lee, 2010). Baddeley proposed that working-memory encompasses a series of slave systems representing different modalities of information (the phonological loop, visuo-spatial sketchpad, and episodic buffer), which in turn are controlled by a central executive (Baddeley, 2000). Working-memory is synonymous to the earlier concept of shortterm memory (Atkinson and Shiffrin, 1968), though the workingmemory model emphasizes that this is not simply a buffer of incoming information but it is involved in a bidirectional flow of information to and from long-term memory. In recent years, the term visual short-term memory has been used in the literature to refer specifically to information contained in simple visual displays (e.g., with multiple colored squares appearing at different locations in the screen), not involving properties that can be represented and manipulated in memory in an abstract form (Todd and Marois, 2004).

Neurophysiological recordings from non-human primates have demonstrated persistent discharges of neurons observed after the offset of sensory stimuli (Figures 3A,B) that subjects were required to remember and recall (Fuster and Alexander, 1971). Furthermore, this persistent activity spanning the delay period of working-memory tasks is tuned to specific stimulus properties (Funahashi et al., 1989). For these reasons, persistent activity is generally considered as the neural correlate of working-memory, providing a mechanism for maintaining in memory the properties of a remembered stimulus (GoldmanRakic, 1995). Recurrent connections between layer $2 / 3$ cortical neurons are considered as the main contributor to the generation and maintenance of persistent discharges (Constantinidis and Wang, 2004). Neurons originally activated by a sensory stimulus continue to excite each other through a dense network of reciprocal connection-such as the extensive network of intrinsic connections reported in area 46 of the PFC (Kritzer and Goldman-Rakic, 1995) allowing activity to reverberate even after the original stimulus is no longer present. Although persistent activity was initially demonstrated in the PFC, it has now been observed in multiple brain regions, including other areas of the association cortex and subcortical regions such as thalamic nuclei and the basal ganglia (Constantinidis and Procyk, 2004; Pasternak and Greenlee, 2005; Rawley and Constantinidis, 2009).

Short-term memory phenomena not based on persistent activity have also been recognized. One such effect has been described in the context of tasks that require comparison of two stimuli presented in sequence. Some neurons respond differentially to the same stimulus depending on whether it matched a previous stimulus or not, and this activity is, therefore, informative about the prior stimulus (Miller et al., 1991). Non-spiking, synaptic mechanisms are thought to mediate this process (Mongillo et al., 2008; Sugase-Miyamoto et al., 2008). In the next paragraphs, we will review the properties of working-memory activity in the dorsolateral PFC and PPC and what they reveal about their common and unique roles in the maintenance of working-memory. 


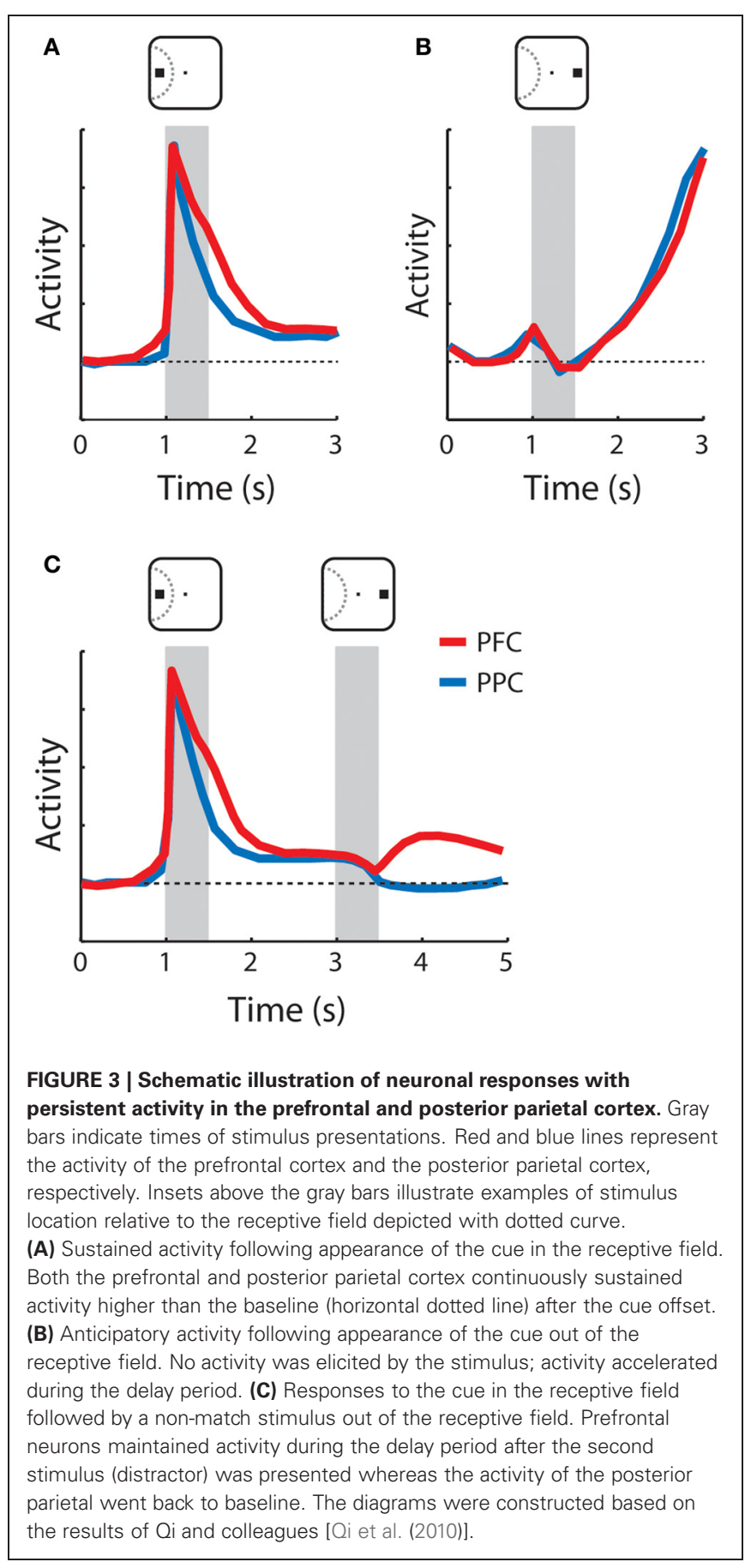

Neurons in the dorsolateral PFC, including the FEF, readily exhibit persistent activity in a wide range of tasks that require working-memory, and this activity represents attributes of the remembered stimulus such as its spatial location, shape, color, and luminance (Fuster et al., 1985; Funahashi et al., 1989; Constantinidis et al., 2001; Armstrong et al., 2009; Meyer et al., 2011). The activity of these neurons is quite heterogeneous in terms of the envelope of neuronal responses but can be classified into two broad categories: activity that appears to extend a response to the stimulus itself and is sustained into the delay period, schematized in Figure 3A, and activity that only begins after the offset of the stimulus and accelerates during the delay period, as shown in Figure 3B (Quintana and Fuster, 1992; Qi et al., 2010). We refer to these types as sustained and anticipatory, respectively. Anticipatory activity has also been associated with prospective memory of an upcoming stimulus or event (Rainer and Miller, 2002). In recent years it has become evident that performance of a working-memory task is not necessary for the emergence of working-memory activity; persistent responses are present even in naïve animals, only required to fixate after the appearance of visual stimuli (Meyer et al., 2007, 2011). Dorsolateral prefrontal neurons also exhibit activity reflective of the properties of a previous stimulus, independent of persistent discharges. A population of prefrontal neurons responds differentially to a stimulus if it appears as a match or a nonmatch, in delayed match-to-sample tasks (Miller et al., 1996; Pasternak and Zaksas, 2003; Kusunoki et al., 2009; Qi et al., 2012).

Posterior parietal neurons are also active in the delay period of working-memory tasks (Gnadt and Andersen, 1988; Constantinidis and Steinmetz, 1996; Chafee et al., 2005), and responses of individual neurons are tuned for the spatial location of the remembered stimulus (Figure 3A). Working-memory capacity represented in the activity of the PFC and PPC appears to be similar (Buschman et al., 2011). Like the PFC (Figures 3A,B), posterior parietal neuronal activity can be classified into sustained and anticipatory (Quintana and Fuster, 1992; Qi et al., 2010). In the PPC too, working-memory activity is present even in naïve animals, only trained to fixate (Constantinidis and Steinmetz, 2005), although this report involved only a very brief delay period. Finally, posterior parietal neurons also exhibit modulation by the match or non-match status of a remembered stimulus (Steinmetz et al., 1994; Rawley and Constantinidis, 2010).

From this review of properties, it is evident that PFC and PPC manifest very similar types of activity-related to workingmemory and it is no surprise that studies comparing the activity of dorsolateral prefrontal and posterior parietal neurons in the same animals have revealed a great deal of similarities. These include similar percentages of neurons activated in the two areas, similar response magnitudes, similar temporal envelopes of responses, and similar tuning characteristics to spatial stimuli (Chafee and Goldman-Rakic, 1998; Qi et al., 2010).

Although there are common features of persistent activity in the PFC and the PPC, different properties between areas have also been identified. One difference has to do with the response patterns during maintenance of a stimulus in memory, when multiple stimuli are presented sequentially (Figure 3C). Prefrontal neurons represent the location of the original stimulus, actively held in memory even after the appearance of distractors (di Pellegrino and Wise, 1993; Qi et al., 2010), while posterior parietal neurons represent the most recent stimulus presentation (Constantinidis and Steinmetz, 1996). We should note, however, that the difference between the areas may be quantitative rather than qualitative. Posterior parietal neurons continue to exhibit small but significant levels of sustained activity following the presentation of a stimulus that serves to summon attention even after the appearance of a distractor (Bisley 
and Goldberg, 2003), and a difference between areas was not apparent in some tasks tested in the same animals (Qi et al., 2010). A second line of evidence for functional specialization between the two regions in working-memory comes from cooling experiments. Cooling of the PFC produces more pronounced performance decreases in spatial working-memory tasks compared to cooling of the PPC, at least in terms of saccadic error around the remembered target (Chafee and Goldman-Rakic, 2000). Finally, a third proposed type of differentiation has to do with the nature of information represented in working-memory for each of the two areas. By virtue of their proximity, the ventrolateral and dorsolateral PFC was proposed to integrate information from both the dorsal and visual streams, particularly as a result of task demands (Rao et al., 1997; Rainer et al., 1998a). Later experiments indicated that parietal neurons have equivalent selectivity for non-spatial information as that described in the PFC (Sereno and Maunsell, 1998; Toth and Assad, 2002). At the same time, experiments recording activity before and after training in tasks that require integration of spatial and non-spatial information reveal that dorsolateral PFC has a clear bias toward the representation of spatial information, both before and after training (Meyer et al., 2011). Therefore, it is questionable whether information content is a significant distinguishing feature between the dorsolateral PFC and PPC in working-memory.

\section{DISTRIBUTED PROCESSING}

The previous sections have highlighted the functional dissociation between PPC and dorsolateral PFC, however, it is important to emphasize that routine execution of a range of cognitive functions depends on both areas, whether they involve distinct or identical patterns. In this sense, concurrent parietal and prefrontal activation during the execution of a cognitive task should not be viewed as a sign of redundancy but could be more appropriately interpreted as a vital element of distributed processing. The necessity of activation of both areas is revealed by the studies such as those relying on cooling to reversibly inactivate either brain area (Quintana et al., 1989; Chafee and Goldman-Rakic, 2000). Even in tasks that fail to differentiate the patterns of activity between areas such as the delayed response task, reversible inactivation of either brain area produces performance impairments, and despite continued presence of activity in the area that was not being inactivated. Behavioral events, therefore, are likely to rely on the concerted action of neurons in multiple cortical areas (Chafee and Goldman-Rakic, 2000).

\section{NEURAL SUBSTRATES OF SPECIALIZATION}

Despite the overall similarity in anatomical inputs and the parallel nature of anatomical projections between the dorsolateral PFC and PPC, a number of anatomical properties differ between these areas, including the influence of various neurotransmitter systems, the intrinsic connectivity within each area, as well as the respective connectivity with other brain regions. Computational models exploring these differences have offered significant insights into the underlying mechanisms mediating functional specialization of each area. In the following sections we will focus on the role of two neurotransmitter systems, dopamine and glutamate, and the patterns of intrinsic connectivity between excitatory and inhibitory neurons in the two regions.

\section{DOPAMINERGIC INNERVATION}

Dopamine has long been viewed as a critical factor of prefrontal function and a unique influence to the PFC compared to its cortical afferents. Dopamine preferentially innervates the frontal lobe, whereas dopaminergic innervation is largely absent from the parietal cortex (Levitt et al., 1984; Haber and Fudge, 1997). Dopamine dysregulation in the PFC has also been implicated in schizophrenia, which is linked to marked impairments in working-memory and executive function (Okubo et al., 1997; Abi-Dargham et al., 2002; Karlsson et al., 2002). Decreased prefrontal activation has been reported in animal models of schizophrenia, which alters dopamine uptake in other brain areas as well (Bertolino et al., 1999; Meyer-Lindenberg et al., 2002). Computational studies have demonstrated persistent discharges with an improved signalto-noise ratio in networks that incorporate dopamine inputs, compared to equivalent networks without dopamine (Durstewitz et al., 2000). Dopamine innervation has also been proposed as a gating mechanism in reinforcement learning, signaling which stimuli predict reward and which are irrelevant (Montague et al., 2004).

Two families of dopamine receptors have been identified, with unique cognitive contributions. D1 dopamine receptors are widely spread in the PFC whereas D2 receptors are more abundant in the striatum (Meador-Woodruff et al., 1996). The former are generally considered responsible for prefrontal-dependent cognitive functions, whereas the latter are the main site of action of antipsychotic drugs (Remington et al., 2011). Local injections of D1 antagonists in the dorsolateral prefrontal cause impairments in performance of both working-memory (Sawaguchi and Goldman-Rakic, 1991, 1994) and attention tasks (Noudoost and Moore, 2011). D1 agonists reverse the cognitive impairments often caused by antipsychotic medication (Castner et al., 2000). D1 receptor stimulation in the dorsolateral PFC is critical for regulating the recurrent microcircuitry of the PFC (GonzalezIslas and Hablitz, 2003; Goldman-Rakic et al., 2004; Arnsten, 2011). Not only does D1 receptor activation facilitate excitatory persistent activity following the appearance of the preferred stimulus of a neuron (Williams and Goldman-Rakic, 1995; Seamans et al., 2001) but it also attenuates excitation to non-preferred locations and, therefore, sharpens spatial tuning during workingmemory (Gao et al., 2001; Paspalas and Goldman-Rakic, 2005; Vijayraghavan et al., 2007). The relative activation of the D1 and D2 receptor systems has been implicated in the regulation of cortical dynamics, with dominance of the D1 system facilitating robust maintenance of information online, and D2 promoting flexibility between tasks and representational states (Durstewitz and Seamans, 2008).

This dynamic modulation by a variety of factors through the actions of dopamine receptors is essentially absent in the PPC and should be viewed as a unique prefrontal specialization. It should be noted, however, that the effects of dopamine modulation are complex, and experimental studies reveal nonmonotonic dosage relationships (Williams and Goldman-Rakic, 1995; Zheng et al., 1999). Differential physiological effects have 
also been observed depending on cortical layer, neuron type, and cellular compartment targeted (Zhou and Hablitz, 1999; Seamans et al., 2001; Gao et al., 2003; Gonzalez-Islas and Hablitz, 2003). Furthermore, the highest concentration of dopamine projections targets the medial PFC, with only a minor proportion innervating the dorsolateral PFC (Lewis et al., 1988). For this reason it is not easy to map specific functional differences between the dorsolateral PFC and PPC to particular aspects of dopamine action.

\section{GLUTAMATE RECEPTORS}

In addition to dopamine involvement, recent studies have revealed that the relative activation of glutamate receptors is important for persistent activity during working-memory (Durstewitz et al., 2000; Seamans et al., 2001; Wang, 2001; Chen et al., 2004; Wang et al., 2008; Arnsten et al., 2010). The density of NMDA receptors compared to AMPA receptors has been identified as critical in this respect (Yang and Seamans, 1996; Durstewitz et al., 2000; Seamans et al., 2001; Wang, 2001; Chen et al., 2004; Wang et al., 2008). NMDA receptors are kinetically slow and once opened leave the postsynaptic neuron in a depolarized state for a longer time, allowing subsequent postsynaptic potentials to continue generating action potentials (Wang, 1999). Resistance to interference may specifically be enhanced through an increased concentration of NMDA receptors, allowing persistent activity to survive the effect of temporary activation of a competing population of neurons (Compte et al., 2000), and a critical difference between PPC and PFC may lie in their AMPA/NMDA ratio (Izquierdo et al., 1998). Additionally the actions of dopamine itself in the PFC are partially attributed to its effects on NMDA receptors (Cepeda et al., 1992; Yang and Seamans, 1996; Seamans et al., 2001; Chen et al., 2004). Therefore, dysfunction of the prefrontal NMDA-mediated microcircuit may result in the dysregulation of dopamine system in the PFC and striatum which would cause cognitive deficits observed in psychiatric disorders (Arnsten, 2011). It has also been reported that dopamine D1 receptors modulate NMDA receptor functions in prefrontal neurons indicating that there is a reciprocal interaction between the NMDA and D1 effects (Chen et al., 2004; Gao and Wolf, 2008). Finally, reduction of NMDA activity in pyramidal circuits causes decrease in GABA, which leads to less tuned neuronal networks (Rao et al., 2000; Kinney et al., 2006).

\section{INTRINSIC EXCITATORY CONNECTIONS}

In both PPC and dorsolateral PFC, retrograde injections of anatomical tracers reveal clusters of neurons activated over a range of distances of several millimeters (Levitt et al., 1993; Kritzer and Goldman-Rakic, 1995). The elemental cortical microcircuit involves clusters of neurons with similar tuning that are interconnected through excitatory connections, and which inhibit neurons with different stimulus preferences (Goldman-Rakic, 1995). By some accounts, prefrontal pyramidal neurons exhibit the most extensive dendritic trees and highest number of spines of any cortical neurons (Elston, 2000, 2003). In the context of computational models, this would be equivalent to a larger "footprint" of connections of a single prefrontal neuron (Compte et al., 2000), which could result in greater stability of the prefrontal network.
However, the precise functional consequences of these anatomical differences have not been explored in depth.

\section{INTERNEURON TYPES}

Differences in interneuron types have been proposed as another unique specialization of the PFC (Wang et al., 2004). Most cortical interneurons are parvalbumin-containing neurons, which correspond to the Fast Spiking category (Krimer et al., 2005; Zaitsev et al., 2005). In the PFC, calbindin-containing interneurons are more numerous than in other cortical areas (Elston and Gonzalez-Albo, 2003). Calbindin interneurons tonically inhibit the dendrites of pyramidal neurons in close vicinity, forming patterns of axonal connections spatially restricted across the length of a cortical column (Conde et al., 1994; Gabbott and Bacon, 1996; Krimer et al., 2005; Zaitsev et al., 2005). It has, therefore, been proposed that calbindin interneurons release pyramidal neurons from inhibition only when the pyramidal neurons have already been activated during working-memory, insulating the network from noise and distractor interference. Indeed, recent physiological evidence suggests that neurons with functional properties that fit the profile of inverted tuning neurons are more abundant in the prefrontal than the parietal cortex (Zhou et al., 2012). Calbindin interneurons may also play other unique roles in the PFC that are absent in the parietal cortex. For example, anterior cingulate projections preferentially innervate calbindin interneurons, providing a means of controlling prefrontal excitability (Medalla and Barbas, 2009, 2010).

\section{SUMMARY AND FUTURE DIRECTIONS}

The studies reviewed in this article point out that the dorsolateral PFC and PPC share a number of functional properties and are co-activated in a range of cognitive operations requiring attention and working-memory, with very similar activity patterns and time courses of activation. This evidence suggests that distributed processing recruiting the two areas is essential for the execution of cognitive functions. Progress has also been made in identifying unique functions of each area. Inactivation of the PFC causes more severe impairments in a wider range of attention, workingmemory and motor functions. Additionally, the PFC is able to resist interference by distracting stimuli during working-memory.

Unresolved issues to be addressed by future neurophysiological studies include the full gamut of cognitive functions that differentiate the two areas, including the extend to which parietal and prefrontal areas exert direct influence on neuronal activity on extrastriate areas, the capacity and duration of memory traces in the prefrontal and parietal cortex and the influence of flexible rules and learning on prefrontal and parietal activity. Additionally, future experiments may reveal the nature of underlying differences that produce this functional specialization in terms of neurotransmitter systems, intrinsic connections, and connections with other brain areas.

\section{ACKNOWLEDGMENTS}

This work was supported by NIH grants EY016773 and EY017077, and the Tab Williams Family Endowment. We wish to thank Bryce Lambert for editorial assistance and Terry Stanford for comments on the manuscript. 


\section{REFERENCES}

Abi-Dargham, A., Mawlawi, O., Lombardo, I., Gil, R., Martinez, D., Huang, Y., Hwang, D. R., Keilp, J., Kochan, L., van Heertum, R., Gorman, J. M., and Laruelle, M. (2002). Prefrontal dopamine D1 receptors and working memory in schizophrenia. J. Neurosci. 22, 3708-3719.

Andersen, R. A., Asanuma, C., Essick, G., and Siegel, R. M. (1990). Corticocortical connections of anatomically and physiologically defined subdivisions within the inferior parietal lobule. J. Comp. Neurol. 296, 65-113.

Arcizet, F., Mirpour, K., and Bisley, J. W. (2011). A pure salience response in posterior parietal cortex. Cereb. Cortex. 21, 2498-2506.

Armstrong, K. M., Chang, M. H., and Moore, T. (2009). Selection and maintenance of spatial information by frontal eye field neurons. J. Neurosci. 29, 15621-15629.

Arnsten, A. F. (2011). Prefrontal cortical network connections: key site of vulnerability in stress and schizophrenia. Int. J. Dev. Neurosci. 29, 215-223.

Arnsten, A. F., Paspalas, C. D., Gamo, N. J., Yang, Y., and Wang, M. (2010). Dynamic network connectivity: a new form of neuroplasticity. Trends. Cogn. Sci. 14, 365-375.

Asaad, W. F., Rainer, G., and Miller, E. K. (2000). Task-specific neural activity in the primate prefrontal cortex. J. Neurophysiol. 84, 451-459.

Asanuma, C., Andersen, R. A., and Cowan, W. M. (1985). The thalamic relations of the caudal inferior parietal lobule and the lateral prefrontal cortex in monkeys: divergent cortical projections from cell clusters in the medial pulvinar nucleus. J. Comp. Neurol. 241, 357-381.

Atkinson, R. C., and Shiffrin, R. M. (1968). "Human memory: a proposed system and its control processes," in The Psychology of Learning and Motivation, eds K. W. Spence and J. T. Spence (London: Academic Press), 89-195.

Averbeck, B. B., Chafee, M. V., Crowe, D. A., and Georgopoulos, A. P. (2002). Parallel processing of serial movements in prefrontal cortex. Proc. Natl. Acad. Sci. U.S.A. 99, 13172-13177.

Baddeley, A. (2000). The episodic buffer: a new component of working memory? Trends Cogn. Sci. 4, 417-423.

Baddeley, A. (2003). Working memory: looking back and looking forward. Nat. Rev. Neurosci. 4, 829-839.
Barbas, H., and Pandya, D. N. (1989). Architecture and intrinsic connections of the prefrontal cortex in the rhesus monkey. J. Comp. Neurol. 286, 353-375.

Barraclough, D. J., Conroy, M. L., and Lee, D. (2004). Prefrontal cortex and decision making in a mixedstrategy game. Nat. Neurosci. 7, 404-410.

Basso, M. A., and Wurtz, R. H. (2002). Neuronal activity in substantia nigra pars reticulata during target selection. J. Neurosci. 22, 1883-1894.

Berdyyeva, T. K., and Olson, C. R. (2010). Rank signals in four areas of macaque frontal cortex during selection of actions and objects in serial order. J. Neurophysiol. 104, 141-159.

Bertolino, A., Knable, M. B., Saunders, R. C., Callicott, J. H., Kolachana, B., Mattay, V. S., Bachevalier, J., Frank, J. A., Egan, M., and Weinberger D. R. (1999). The relationship between dorsolateral prefrontal $\mathrm{N}$-acetylaspartate measures and striatal dopamine activity in schizophrenia. Biol. Psychiatry 45, 660-667.

Bisley, J. W., and Goldberg, M. E. (2003). Neuronal activity in the lateral intraparietal area and spatial attention. Science 299, 81-86.

Bisley, J. W., and Goldberg, M. E. (2010). Attention, intention, and priority in the parietal lobe. Annu. Rev. Neurosci. 33, 1-21.

Blatt, G. J., Andersen, R. A., and Stoner, G. R. (1990). Visual receptive field organization and corticocortical connections of the lateral intraparietal area (area LIP) in the macaque. J. Comp. Neurol. 299, 421-445.

Bruce, C. J., Goldberg, M. E., Bushnell, M. C., and Stanton, G. B. (1985). Primate frontaleye fields. II. Physiological anatomical correlates of electrically evoked eye movements. J. Neurophysiol. 54 714-734.

Buschman, T. J., and Miller, E. K. (2007). Top-down versus bottomup control of attention in the prefrontal and posterior parietal cortices. Science 315, 1860-1862.

Buschman, T. J., Siegel, M., Roy, J. E., and Miller, E. K. (2011). Neural substrates of cognitive capacity limitations. Proc. Natl. Acad. Sci. U.S.A. 108, 11252-11255.

Bushnell, M. C., Goldberg, M. E., and Robinson, D. L. (1981). Behavioral enhancement of visual responses in monkey cerebral cortex. I. Modulation in posterior parietal cortex related to selective visual attention. J. Neurophysiol. 46, 755-772.

Carrasco, M. (2011). Visual attention: the past 25 years. Vision Res. 51, 1484-1525.

Castner, S. A., Williams, G. V., and Goldman-Rakic, P. S. (2000). Reversal of antipsychotic-induced working memory deficits by short-term dopamine D1 receptor stimulation. Science 287 2020-2022.

Cavada, C., and Goldman-Rakic, P. S. (1989a). Posterior parietal cortex in rhesus monkey: I. Parcellation of areas based on distinctive limbic and sensory corticocortical connections. J. Comp. Neurol. 287, 393-421.

Cavada, C., and Goldman-Rakic, P. S. (1989b). Posterior parietal cortex in rhesus monkey: II. Evidence for segregated corticocortical networks linking sensory and limbic areas with the frontal lobe. J. Comp. Neurol. 287, 422-445.

Cepeda, C., Radisavljevic, Z., Peacock, W., Levine, M. S., and Buchwald, N. A. (1992). Differential modulation by dopamine of responses evoked by excitatory amino acids in human cortex. Synapse 11, 330-341.

Chafee, M. V., Crowe, D. A., Averbeck, B. B., and Georgopoulos, A. P. (2005). Neural correlates of spatia judgement during object construction in parietal cortex. Cereb. Cortex 15, 1393-1413.

Chafee, M. V., and Goldman-Rakic, P. S. (1998). Matching patterns of activity in primate prefrontal area 8 and parietal area 7ip neurons during a spatial working memory task. J. Neurophysiol. 79, 2919-2940.

Chafee, M. V., and Goldman-Rakic, P. S. (2000). Inactivation of parietal and prefrontal cortex reveals interdependence of neural activity during memory guided-saccades. J. Neurophysiol. 83, 1550-1566.

Chen, G., Greengard, P., and Yan, Z. (2004). Potentiation of NMDA receptor currents by dopamine D1 receptors in prefrontal cortex. Proc. Natl. Acad. Sci. U.S.A. 101 2596-2600.

Cisek, P., and Kalaska, J. F. (2010). Neural mechanisms for interacting with a world full of action choices. Annu. Rev. Neurosci. 33, 269-298.

Compte, A., Brunel, N., GoldmanRakic, P. S., and Wang, X. J. (2000). Synaptic mechanisms and network dynamics underlying spatial working memory in a cortical network model. Cereb. Cortex 10, 910-923.

Conde, F., Lund, J. S., Jacobowitz, D. M., Baimbridge, K. G., and Lewis, D. A. (1994). Local circuit neurons immunoreactive for calretinin, calbindin D-28k or parvalbumin in monkey prefrontal cortex: distribution and morphology. J. Comp. Neurol. 341, 95-116.

Connor, C. E., Egeth, H. E., and Yantis, S. (2004). Visual attention: bottomup versus top-down. Curr. Biol. 14, R850-R852.

Constantinidis, C. (2006). Posterior parietal mechanisms of visual attention. Rev. Neurosci. 17, 415-427.

Constantinidis, C., Franowicz, M. N., and Goldman-Rakic, P. S. (2001). The sensory nature of mnemonic representation in the primate prefrontal cortex. Nat. Neurosci. 4, 311-316.

Constantinidis, C., and Procyk, E. (2004). The primate working memory networks. Cogn. Affect. Behav Neurosci. 4, 444-465.

Constantinidis, C., and Steinmetz, M. A. (1996). Neuronal activity in posterior parietal area 7a during the delay periods of a spatial memory task. J. Neurophysiol. 76, 1352-1355.

Constantinidis, C., and Steinmetz, M. A. (2001). Neuronal responses in area $7 \mathrm{a}$ to multiple stimulus displays: I. Neurons encode the location of the salient stimulus. Cereb. Cortex 11, 581-591.

Constantinidis, C., and Steinmetz, M. A. (2005). Posterior parietal cortex automatically encodes the location of salient stimuli. J. Neurosci. 25, 233-238.

Constantinidis, C., and Wang, X. J. (2004). A neural circuit basis for spatial working memory. Neuroscientist 10, 553-565.

Corbetta, M., and Shulman, G. L (2002). Control of goal-directed and stimulus-driven attention in the brain. Nat. Rev. Neurosci. 3, 201-215.

Crowe, D. A., Averbeck, B. B., Chafee, M. V., and Georgopoulos, A. P. (2005). Dynamics of parietal neural activity during spatial cognitive processing. Neuron 47, 885-891.

Cui, H., and Andersen, R. A. (2007). Posterior parietal cortex encodes autonomously selected motor plans. Neuron 56, 552-559.

Curtis, C. E., and Lee, D. (2010). Beyond working memory: the role of persistent activity in decision making. Trends Cogn. Sci. 14, 216-222.

Cutrell, E. B., and Marrocco, R. T. (2002). Electrical microstimulation of primate posterior parietal cortex initiates orienting and alerting components of covert attention. Exp. Brain Res. 144, 103-113.

di Pellegrino, G., and Wise, S. P. (1993). Effects of attention on 
visuomotor activity in the premotor and prefrontal cortex of a primate. Somatosens. Mot. Res. 10, 245-262.

Douglas, R. J., and Martin, K. A. (2004). Neuronal circuits of the neocortex. Annu. Rev. Neurosci. 27, 419-451.

Douglas, R. J., and Martin, K. A. (2007). Recurrent neuronal circuits in the neocortex. Curr. Biol. 17, R496-R500.

Duncan, J., and Humphreys, G. W. (1989). Visual search and stimulus similarity. Psychol. Rev. 96, 433-458.

Durstewitz, D., and Seamans, J. K. (2008). The dual-state theory of prefrontal cortex dopamine function with relevance to catecholo-methyltransferase genotypes and schizophrenia. Biol. Psychiatry 64, 739-749.

Durstewitz, D., Seamans, J. K., and Sejnowski, T. J. (2000). Dopamine-mediated stabilization of delay-period activity in a network model of prefrontal cortex. J. Neurophysiol. 83, 1733-1750.

Elston, G. N. (2000). Pyramidal cells of the frontal lobe: all the more spinous to think with. J. Neurosci. 20, RC95.

Elston, G. N. (2003). The pyramidal neuron in occipital, temporal and prefrontal cortex of the owl monkey (Aotus trivirgatus): regional specialization in cell structure. Eur. J. Neurosci. 17, 1313-1318.

Elston, G. N., and Gonzalez-Albo, M. C. (2003). Parvalbumin-, calbindin-, and calretinin-immunoreactive neurons in the prefrontal cortex of the owl monkey (Aotus trivirgatus): a standardized quantitative comparison with sensory and motor areas. Brain Behav. Evol. 62, 19-30.

Felleman, D. J., and van Essen, D. C. (1991). Distributed hierarchical processing in the primate cerebral cortex. Cereb. Cortex 1, 1-47.

Fitzgerald, J. K., Freedman, D. J., and Assad, J. A. (2011). Generalized associative representations in parietal cortex. Nat. Neurosci. 14, 1075-1079.

Freedman, D. J., and Assad, J. A. (2006). Experience-dependent representation of visual categories in parietal cortex. Nature 443, 85-88.

Freedman, D. J., Riesenhuber, M., Poggio, T., and Miller, E. K. (2001). Categorical representation of visual stimuli in the primate prefrontal cortex. Science 291, 312-316.

Funahashi, S., Bruce, C. J., and Goldman-Rakic, P. S. (1989). Mnemonic coding of visual space in the monkey's dorsolateral prefrontal cortex. J. Neurophysiol. 61, 331-349.

Fuster, J. M., and Alexander, G. E. (1971). Neuron activity related to short-term memory. Science 173, 652-654.

Fuster, J. M., Bauer, R. H., and Jervey, J. P. (1985). Functional interactions between inferotemporal and prefrontal cortex in a cognitive task. Brain Res. 330, 299-307.

Gabbott, P. L., and Bacon, S. J. (1996). Local circuit neurons in the medial prefrontal cortex (areas 24a,b,c, 25 and 32) in the monkey: I. Cell morphology and morphometrics. J. Comp. Neurol. 364, 567-608.

Gao, W. J., Krimer, L. S., and GoldmanRakic, P. S. (2001). Presynaptic regulation of recurrent excitation by D1 receptors in prefrontal circuits. Proc. Natl. Acad. Sci. U.S.A. 98 295-300.

Gao, W. J., Wang, Y., and GoldmanRakic, P. S. (2003). Dopamine modulation of perisomatic and peridendritic inhibition in prefrontal cortex. J. Neurosci. 23, 1622-1630.

Gao, C., and Wolf, M. E. (2008). Dopamine receptors regulate NMDA receptor surface expression in prefrontal cortex neurons. J. Neurochem. 106, 2489-2501.

Gnadt, J. W., and Andersen, R. A. (1988). Memory related motor planning activity in posterior parietal cortex of macaque. Exp. Brain Res. 70, 216-220.

Goldman-Rakic, P. S. (1987). "Circuitry of the prefrontal cortex and the regulation of behavior by representational knowledge," in Handbook of Physiology, eds F. Plum and V. B. Mountcastle (Bethesda, MD: American Physiological Society), 373-417.

Goldman-Rakic, P. S. (1995). Cellular basis of working memory. Neuron 14, 477-485.

Goldman-Rakic, P. S., Castner, S. A. Svensson, T. H., Siever, L. J., and Williams, G. V. (2004). Targeting the dopamine D1 receptor in schizophrenia: insights for cognitive dysfunction. Psychopharmacology (Berl) 174, 3-16.

Gonzalez-Islas, C., and Hablitz, J. J. (2003). Dopamine enhances EPSCs in layer II-III pyramidal neurons in rat prefrontal cortex. J. Neurosci. 23, 867-875.

Gottlieb, J., and Balan, P. (2010). Attention as a decision in information space. Trends Cogn. Sci. 14, 240-248.

Gottlieb, J. P., Kusunoki, M., and Goldberg, M. E. (1998). The representation of visual salience in monkey parietal cortex. Nature 391, 481-484.

Haber, S. N., and Fudge, J. L. (1997) The primate substantia nigra and VTA: integrative circuitry and function. Crit. Rev. Neurobiol. 11 323-342.

Hoshi, E., and Tanji, J. (2004). Areaselective neuronal activity in the dorsolateral prefrontal cortex for information retrieval and action planning. J. Neurophysiol. 91, 2707-2722.

Hubel, D. H., and Wiesel, T. N. (1962). Receptive fields, binocular interaction and functional architecture in the cat's visual cortex. J. Physiol. 160 106-154.

Hubel, D. H., and Wiesel, T. N (1965). Receptive fields and functional architecture in two nonstriate visual areas (18 and 19) of the cat. J. Neurophysiol. 28, 229-289.

Huerta, M. F., Krubitzer, L. A., and Kaas, J. H. (1986). Frontal eye field as defined by intracortical microstimulation in squirrel monkeys, owl monkeys, and macaque monkeys: I. Subcortical connections. J. Comp. Neurol. 253, 415-439.

Iba, M., and Sawaguchi, T. (2003). Involvement of the dorsolateral prefrontal cortex of monkeys in visuospatial target selection. J. Neurophysiol. 89, 587-599.

Inoue, M., and Mikami, A. (2006) Prefrontal activity during serial probe reproduction task: encoding, mnemonic, and retrieval processes. J. Neurophysiol. 95, 1008-1041.

Ipata, A. E., Gee, A. L., Goldberg, M. E., and Bisley, J. W. (2006). Activity in the lateral intraparietal area predicts the goal and latency of saccades in a free-viewing visual search task. J. Neurosci. 26, 3656-3661.

Itti, L., and Koch, C. (2001). Computational modelling of visual attention. Nat. Rev. Neurosci. 2, 194-203.

Izquierdo, I., Izquierdo, L. A., Barros, D. M., Mello E Souza, T., de Souza M. M., Quevedo, J., Rodrigues, C., Sant'anna, M. K., Madruga, M., and Medina, J. H. (1998). Differential involvement of cortical receptor mechanisms in working, short-term and long-term memory. Behav. Pharmacol. 9, 421-427.

Jouve, B., Rosenstiehl, P., and Imbert, M. (1998). A mathematical approach to the connectivity between the cortical visual areas of the macaque monkey. Cereb. Cortex 8, 28-39.

Karlsson, P., Farde, L., Halldin, C. and Sedvall, G. (2002). PET study of $\mathrm{D}(1)$ dopamine receptor binding in neuroleptic-naive patients with schizophrenia. Am. J. Psychiatry 159, 761-767.

Kim, J. N., and Shadlen, M. N. (1999). Neural correlates of a decision in the dorsolateral prefrontal cortex of the macaque. Nat. Neurosci. 2, 176-185.

Kinney, J. W., Davis, C. N., Tabarean, I., Conti, B., Bartfai, T., and Behrens, M. M. (2006). A specific role for NR2A-containing NMDA receptors in the maintenance of parvalbumin and GAD67 immunoreactivity in cultured interneurons. J. Neurosci. 26, 1604-1615.

Koch, C., and Ullman, S. (1985). Shifts in selective visual attention: towards the underlying neural circuitry. Hum. Neurobiol. 4, 219-227.

Krimer, L. S., Zaitsev, A. V., Czanner, G., Kroner, S., Gonzalez-Burgos, G., Povysheva, N. V., Iyengar, S. Barrionuevo, G., and Lewis, D. A. (2005). Cluster analysis-based physiological classification and morphological properties of inhibitory neurons in layers 2-3 of monkey dorsolateral prefrontal cortex. J. Neurophysiol. 94, 3009-3022.

Kritzer, M. F., and Goldman-Rakic, P. S. (1995). Intrinsic circuit organization of the major layers and sublayers of the dorsolateral prefrontal cortex in the rhesus monkey. J. Comp. Neurol. 359, 131-143.

Kusunoki, M., Gottlieb, J., and Goldberg, M. E. (2000). The lateral intraparietal area as a salience map: the representation of abrupt onset, stimulus motion, and task relevance. Vision Res. 40, 1459-1468.

Kusunoki, M., Sigala, N., Gaffan, D., and Duncan, J. (2009). Detection of fixed and variable targets in the monkey prefrontal cortex. Cereb. Cortex 19, 2522-2534.

Lebedev, M. A., Messinger, A., Kralik, J. D., and Wise, S. P. (2004). Representation of attended versus remembered locations in prefrontal cortex. PLoS Biol. 2:e365. doi: 10.1371/journal.pbio.0020365. [Epub 2004 Oct 2026].

Leon, M. I., and Shadlen, M. N. (1999). Effect of expected reward magnitude on the response of neurons in the dorsolateral prefrontal cortex of the macaque. Neuron 24, 415-425.

Levitt, J. B., Lewis, D. A., Yoshioka, T., and Lund, J. S. (1993). Topography of pyramidal neuron intrinsic connections in macaque monkey prefrontal cortex (areas 9 and 46). J. Comp. Neurol. 338, 360-376.

Levitt, P., Rakic, P., and GoldmanRakic, P. (1984). Region-specific distribution of catecholamine afferents in primate cerebral cortex: a fluorescence histochemical analysis. J. Comp. Neurol. 227, 23-36.

Lewis, D. A., Foote, S. L., Goldstein, M., and Morrison, J. H. (1988). The dopaminergic innervation of 
monkey prefrontal cortex: a tyrosine hydroxylase immunohistochemical study. Brain Res. 449, 225-243.

Liu, Y., Yttri, E. A., and Snyder, L. H. (2010). Intention and attention: different functional roles for LIPd and LIPv. Nat. Neurosci. 13, 495-500.

Lynch, J. C., Graybiel, A. M., and Lobeck, L. J. (1985). The differential projection of two cytoarchitectonic subregions of the inferior parietal lobule of macaque upon the deep layers of the superior colliculus. J. Comp. Neurol. 235, 241-254.

Lynch, J. C., Hoover, J. E., and Strick, P. L. (1994). Input to the primate frontal eye field from the substantia nigra, superior colliculus, and dentate nucleus demonstrated by transneuronal transport. Exp. Brain Res. 100, 181-186.

Macko, K. A., Jarvis, C. D., Kennedy, C., Miyaoka, M., Shinohara, M., Sololoff, L., and Mishkin, M. (1982). Mapping the primate visual system with [2-14C]deoxyglucose. Science 218, 394-397.

McPeek, R. M., and Keller, E. L. (2002). Saccade target selection in the superior colliculus during a visual search task. J. Neurophysiol. 88, 2019-2034.

Meador-Woodruff, J. H., Damask, S. P., Wang, J., Haroutunian, V., Davis, K. L., and Watson, S. J. (1996). Dopamine receptor mRNA expression in human striatum and neocortex. Neuropsychopharmacology 15, 17-29.

Medalla, M., and Barbas, H. (2009). Synapses with inhibitory neurons differentiate anterior cingulate from dorsolateral prefrontal pathways associated with cognitive control. Neuron 61, 609-620.

Medalla, M., and Barbas, H. (2010). Anterior cingulate synapses in prefrontal areas 10 and 46 suggest differential influence in cognitive control. J. Neurosci. 30, 16068-16081.

Meyer-Lindenberg, A., Miletich, R. S. Kohn, P. D., Esposito, G., Carson, R. E., Quarantelli, M., Weinberger, D. R., and Berman, K. F. (2002). Reduced prefrontal activity predicts exaggerated striatal dopaminergic function in schizophrenia. Nat. Neurosci. 5, 267-271.

Meyer, T., Qi, X. L., and Constantinidis, C. (2007). Persistent discharges in the prefrontal cortex of monkeys naive to working memory tasks. Cereb. Cortex 17(Suppl. 1), i70-i76.

Meyer, T., Qi, X. L., Stanford, T. R., and Constantinidis, C. (2011). Stimulus selectivity in dorsal and ventral prefrontal cortex after training in working memory tasks. J. Neurosci. 31, 6266-6276.
Miller, E. K., and Cohen, J. D. (2001). An integrative theory of prefrontal cortex function. Annu. Rev. Neurosci. 24, 167-202.

Miller, E. K., Erickson, C. A., and Desimone, R. (1996). Neural mechanisms of visual working memory in prefrontal cortex of the macaque. J. Neurosci. 16, 5154-5167.

Miller, E. K., Li, L., and Desimone, R. (1991). A neural mechanism for working and recognition memory in inferior temporal cortex. Science 254, 1377-1379.

Mirpour, K., Ong, W. S., and Bisley, J. W. (2010). Microstimulation of posterior parietal cortex biases the selection of eye movement goals during search. J. Neurophysiol. 104 3021-3028.

Mongillo, G., Barak, O., and Tsodyks, M. (2008). Synaptic theory of working memory. Science 319, 1543-1546.

Montague, P. R., Hyman, S. E., and Cohen, J. D. (2004). Computational roles for dopamine in behavioural control. Nature 431, 760-767.

Moore, T., and Armstrong, K. M. (2003). Selective gating of visual signals by microstimulation of frontal cortex. Nature 421, 370-373.

Moore, T., and Fallah, M. (2001). Control of eye movements and spatial attention. Proc. Natl. Acad. Sci. U.S.A. 98, 1273-1276.

Moore, T., and Fallah, M. (2004). Microstimulation of the frontal eye field and its effects on covert spatial attention. J. Neurophysiol. 91, 152-162.

Nieder, A., Freedman, D. J., and Miller, E. K. (2002). Representation of the quantity of visual items in the primate prefrontal cortex. Science 297, 1708-1711.

Nieder, A., and Miller, E. K. (2004). A parieto-frontal network for visual numerical information in the monkey. Proc. Natl. Acad. Sci. U.S.A. 101, 7457-7462. [Epub 2004 May 7453].

Noudoost, B., and Moore, T. (2011). Control of visual cortical signals by prefrontal dopamine. Nature 474, 372-375.

Okubo, Y., Suhara, T., Suzuki, K., Kobayashi, K., Inoue, O., Terasaki, O., Someya, Y., Sassa, T., Sudo, Y., Matsushima, E., Iyo, M., Tateno, Y., and Toru, M. (1997). Decreased prefrontal dopamine D1 receptors in schizophrenia revealed by PET. Nature 385, 634-636.

Pandya, D. N., and Seltzer, B. (1982). Intrinsic connections and architectonics of posterior parietal cortex in the rhesus monkey. J. Comp. Neurol. 204, 196-210.
Paspalas, C. D., and Goldman-Rakic, P. S. (2005). Presynaptic D1 dopamine receptors in primate prefrontal cortex: target-specific expression in the glutamatergic synapse. J. Neurosci. $25,1260-1267$.

Pasternak, T., and Greenlee, M. W. (2005). Working memory in primate sensory systems. Nat. Rev. Neurosci. 6, 97-107.

Pasternak, T., and Zaksas, D. (2003). Stimulus specificity and temporal dynamics of working memory for visual motion. J. Neurophysiol. 90, 2757-2762.

Petrides, M., and Pandya, D. N. (1994) "Comparative architectonic analysis of the human and the macaque frontal cortex," in Handbook of Neuropsychology, eds F. Boller and J. Grafman. (New York, NY: Elsevier) 17-58.

Platt, M. L., and Glimcher, P. W. (1999). Neural correlates of decision variables in parietal cortex. Nature 400 233-238.

Premereur, E., Vanduffel, W., and Janssen, P. (2011). Functional heterogeneity of macaque lateral intraparietal neurons. J. Neurosci. 31 12307-12317.

Preuss, T. M., and Goldman-Rakic, P. S. (1991). Architectonics of the parietal and temporal association cortex in the strepsirhine primate Galago compared to the anthropoid primate Macaca. J. Comp. Neurol. 310 475-506.

Qi, X. L., Katsuki, F., Meyer, T., Rawley, J. B., Zhou, X., Douglas, K. L., and Constantinidis, C. (2010) Comparison of neural activity related to working memory in primate dorsolateral prefrontal and posterior parietal cortex. Front. Syst. Neurosci. 4:12. doi 10.3389/fnsys. 2010.00012

Qi, X. L., Meyer, T., Stanford, T. R., and Constantinidis, C. (2012). Neural correlates of a decision vari able before learning to perform a Match/Nonmatch task. J. Neurosci. (in press).

Quintana, J., and Fuster, J. M. (1992). Mnemonic and predictive functions of cortical neurons in a memory task. Neuroreport 3, 721-724.

Quintana, J., Fuster, J. M., and Yajeya, J. (1989). Effects of cooling parietal cortex on prefrontal units in delay tasks. Brain Res. 503, 100-110.

Rainer, G., Asaad, W. F., and Miller, E. K. (1998a). Memory fields of neurons in the primate prefrontal cortex. Proc. Natl. Acad. Sci. U.S.A. 95 15008-15013.

Rainer, G., Asaad, W. F., and Miller, E. K. (1998b). Selective representation of relevant information by neurons in the primate prefrontal cortex. Nature 393, 577-579.

Rainer, G., and Miller, E. K. (2002). Timecourse of object-related neural activity in the primate prefrontal cortex during a short-term memory task. Eur. J. Neurosci. 15, 1244-1254.

Rao, S. C., Rainer, G., and Miller, E. K. (1997). Integration of what and where in the primate prefrontal cortex. Science 276, 821-824.

Rao, S. G., Williams, G. V., and Goldman-Rakic, P. S. (2000). Destruction and creation of spatial tuning by disinhibition: GABA(A) blockade of prefrontal cortical neurons engaged by working memory. J. Neurosci. 20, 485-494.

Rawley, J. B., and Constantinidis, C. (2009). Neural correlates of learning and working memory in the primate posterior parietal cortex. Neurobiol. Learn. Mem. 91, 129-138.

Rawley, J. B., and Constantinidis, C. (2010). Effects of task and coordinate frame of attention in area $7 \mathrm{a}$ of the primate posterior parietal cortex. J. Vis. 10, 1-16.

Remington, G., Agid, O., and Foussias, G. (2011). Schizophrenia as a disorder of too little dopamine: implications for symptoms and treatment. Expert Rev. Neurother. 11, 589-607.

Robinson, D. L., Goldberg, M. E., and Stanton, G. B. (1978). Parietal association cortex in the primate: sensory mechanisms and behavioral modulations. J. Neurophysiol. 41, 910-932.

Rockland, K. S., and van Hoesen, G. W. (1999). Some temporal and parietal cortical connections converge in CAl of the primate hippocampus. Cereb. Cortex 9, 232-237.

Roitman, J. D., Brannon, E. M., and Platt, M. L. (2007). Monotonic coding of numerosity in macaque lateral intraparietal area. PLoS Biol. 5:e208. doi: 10.1371/journal.pbio.0050208

Sato, T. R., Watanabe, K., Thompson, K. G., and Schall, J. D. (2003). Effect of target-distractor similarity on FEF visual selection in the absence of the target. Exp. Brain Res. 151, 356-363. [Epub 2003 Jun 2012].

Sawaguchi, T., and Goldman-Rakic, P. S. (1991). D1 dopamine receptors in prefrontal cortex: involvement in working memory. Science 251, 947-950.

Sawaguchi, T., and Goldman-Rakic, P. S. (1994). The role of D1dopamine receptor in working 
memory: local injections of dopamine antagonists into the prefrontal cortex of rhesus monkeys performing an oculomotor delayedresponse task. J. Neurophysiol. 71, 515-528.

Schall, J. D. (2002). The neural selection and control of saccades by the frontal eye field. Philos. Trans. R. Soc. Lond. B Biol. Sci. 357, 1073-1082.

Schall, J. D., and Hanes, D. P. (1993). Neural basis of saccade target selection in frontal eye field during visual search. Nature 366, 467-469.

Schall, J. D., Hanes, D. P., Thompson, K. G., and King, D. J. (1995). Saccade target selection in frontal eye field of macaque. I. Visual and premovement activation. J. Neurosci. 15, 6905-6918.

Schall, J. D., Pare, M., and Woodman, G. F. (2007). Comment on "Topdown versus bottom-up control of attention in the prefrontal and posterior parietal cortices." Science $318,44$.

Schall, J. D., and Thompson, K. G. (1999). Neural selection and control of visually guided eye movements. Annu. Rev. Neurosci. 22, 241-259.

Schwartz, M. L., and Goldman-Rakic, P. S. (1984). Callosal and intrahemispheric connectivity of the prefrontal association cortex in rhesus monkey: relation between intraparietal and principal sulcal cortex. J. Comp. Neurol. 226, 403-420.

Seamans, J. K., Durstewitz, D., Christie, B. R., Stevens, C. F., and Sejnowski, T. J. (2001). Dopamine D1/D5 receptor modulation of excitatory synaptic inputs to layer $\mathrm{V}$ prefrontal cortex neurons. Proc. Natl. Acad. Sci. U.S.A. 98, 301-306.

Segraves, M. A., and Goldberg, M. E. (1987). Functional properties of corticotectal neurons in the monkey's frontal eye field. J. Neurophysiol. 58, 1387-1419.

Selemon, L. D., and Goldman-Rakic, P. S. (1988). Common cortical and subcortical targets of the dorsolateral prefrontal and posterior parietal cortices in the rhesus monkey: evidence for a distributed neural network subserving spatially guided behavior. J. Neurosci. 8, 4049-4068.

Sereno, A. B., and Maunsell, J. H. (1998). Shape selectivity in primate lateral intraparietal cortex. Nature 395, 500-503.

Shadlen, M. N., and Newsome, W. T. (1996). Motion perception: seeing and deciding. Proc. Natl. Acad. Sci. U.S.A. 93, 628-633.
Shibutani, H., Sakata, H., and Hyvarinen, J. (1984). Saccade and blinking evoked by microstimulation of the posterior parietal association cortex of the monkey. Exp. Brain Res. 55, 1-8.

Shima, K., Isoda, M., Mushiake, H., and Tanji, J. (2007). Categorization of behavioural sequences in the prefrontal cortex. Nature 445, 315-318.

Snyder, L. H., Batista, A. P., and Andersen, R. A. (1997). Coding of intention in the posterior parietal cortex. Nature 386, 167-170.

Sommer, M. A., and Wurtz, R. H. (1998). Frontal eye field neurons orthodromically activated from the superior colliculus. J. Neurophysiol. 80, 3331-3335.

Sommer, M. A., and Wurtz, R. H. (2002). A pathway in primate brain for internal monitoring of movements. Science 296, 1480-1482.

Stanton, G. B., Bruce, C. J., and Goldberg, M. E. (1995). Topography of projections to posterior cortical areas from the macaque frontal eye fields. J. Comp. Neurol. 353, 291-305.

Steinmetz, M. A., Connor, C. E., Constantinidis, C., and McLaughlin, J. R. (1994). Covert attention suppresses neuronal responses in area $7 \mathrm{a}$ of the posterior parietal cortex. J. Neurophysiol. 72, 1020-1023.

Steinmetz, M. A., and Constantinidis, C. (1995). Neurophysiological evidence for a role of posterior parietal cortex in redirecting visual attention. Cereb. Cortex 5, 448-456.

Stoet, G., and Snyder, L. H. (2004) Single neurons in posterior parietal cortex of monkeys encode cognitive set. Neuron 42, 1003-1012.

Sugase-Miyamoto, Y., Liu, Z., Wiener, M. C., Optican, L. M., and Richmond, B. J. (2008). Short-term memory trace in rapidly adapting synapses of inferior temporal cortex. PLoS Comput. Biol. 4:e1000073. doi: 10.1371/journal.pcbi.1000073

Sugrue, L. P., Corrado, G. S., and Newsome, W. T. (2004). Matching behavior and the representation of value in the parietal cortex. Science 304, 1782-1787.

Swaminathan, S. K., and Freedman, D. J. (2012). Preferential encoding of visual categories in parietal cortex compared with prefrontal cortex. Nat. Neurosci. 15, 315-320.

Thomas, N. W., and Pare, M. (2007). Temporal processing of saccade targets in parietal cortex area LIP during visual search. J. Neurophysiol. 97, 942-947.
Thompson, K. G., Bichot, N. P., and Schall, J. D. (1997). Dissociation of visual discrimination from saccade programming in macaque frontal eye field. J. Neurophysiol. 77, 1046-1050.

Thompson, K. G., Hanes, D. P. Bichot, N. P., and Schall, J. D. (1996). Perceptual and motor processing stages identified in the activity of macaque frontal eye field neurons during visual search. J. Neurophysiol. 76, 4040-4055.

Todd, J. J., and Marois, R. (2004). Capacity limit of visual short-term memory in human posterior parietal cortex. Nature 428, 751-754.

Toth, L. J., and Assad, J. A. (2002). Dynamic coding of behaviourally relevant stimuli in parietal cortex. Nature 415, 165-168.

Treisman, A. M., and Gelade, G. (1980). A feature-integration theory of attention. Cogn. Psychol. 12, 97-136.

Ungerleider, L. G., Galkin, T. W. Desimone, R., and Gattass, R. (2008). Cortical connections of area V4 in the macaque. Cereb. Cortex $18,477-499$.

Ungerleider, L. G., and Haxby, J. V. (1994). 'What' and 'where' in the human brain. Curr. Opin. Neurobiol. 4, 157-165.

Ungerleider, L. G., and Mishkin, M. (1982). "Two cortical visual systems," in Analysis of Visual Behavior eds D. J. Ingle, M. A. Goodale, and R. J. W. Mansfield (Cambridge, MA: MIT Press), 549-586.

van Essen, D. C., Anderson, C. H., and Felleman, D. J. (1992). Information processing in the primate visual system: an integrated systems perspective. Science 255 , 419-423.

Vijayraghavan, S., Wang, M. Birnbaum, S. G., Williams, G. V., and Arnsten, A. F. (2007) Inverted-U dopamine D1 receptor actions on prefrontal neurons engaged in working memory. Nat. Neurosci. 10, 376-384.

Wallis, J. D., Anderson, K. C., and Miller, E. K. (2001). Single neurons in prefrontal cortex encode abstract rules. Nature 411, 953-956.

Wang, X. J. (1999). Synaptic basis of cortical persistent activity: the importance of NMDA receptors to working memory. J. Neurosci. 19, 9587-9603.

Wang, X. J. (2001). Synaptic reverberation underlying mnemonic persistent activity. Trends Neurosci. 24 455-463.

Wang, H., Stradtman, G. G. 3rd, Wang, X. J., and Gao, W. J. (2008).
A specialized NMDA receptor function in layer 5 recurrent microcircuitry of the adult rat prefrontal cortex. Proc. Natl. Acad. Sci. U.S.A. 105, 16791-16796.

Wang, X. J., Tegner, J., Constantinidis, C., and Goldman-Rakic, P. S. (2004). Division of labor among distinct subtypes of inhibitory neurons in a cortical microcircuit of working memory. Proc. Natl. Acad. Sci. U.S.A. 101, 1368-1373.

Wardak, C., Ibos, G., Duhamel, J. R., and Olivier, E. (2006). Contribution of the monkey frontal eye field to covert visual attention. J. Neurosci. 26, 4228-4235.

Wardak, C., Olivier, E., and Duhamel, J. R. (2002). Saccadic target selection deficits after lateral intraparietal area inactivation in monkeys. J. Neurosci. 22, 9877-9884

Wardak, C., Olivier, E., and Duhamel, J. R. (2004). A deficit in covert attention after parietal cortex inactivation in the monkey. Neuron 42, 501-508.

White, I. M., and Wise, S. P. (1999). Rule-dependent neuronal activity in the prefrontal cortex. Exp. Brain Res. 126, 315-335

Williams, G. V., and Goldman-Rakic, P. S. (1995). Modulation of memory fields by dopamine D1 receptors in prefrontal cortex. Nature 376, 572-575.

Wolfe, J. M. (1994). Guided search 2.0 a revised model of visual-search. Psychon. Bull. Rev. 1, 202-238.

Wolfe, J. M. (2010). Visual search. Curr. Biol. 20, R346-R349.

Wolfe, J. M., and Horowitz, T. S. (2004). What attributes guide the deployment of visual attention and how do they do it? Nat. Rev. Neurosci. 5, 495-501.

Yang, C. R., and Seamans, J. K. (1996). Dopamine D1 receptor actions in layers V-VI rat prefrontal cortex neurons in vitro: modulation of dendritic-somatic signal integration. J. Neurosci. 16, 1922-1935

Yang, T., and Shadlen, M. N. (2007). Probabilistic reasoning by neurons. Nature 447, 1075-1080.

Yin, T. C., and Mountcastle, V. B. (1978). Mechanisms of neural integration in the parietal lobe for visual attention. Fed. Proc. 37 2251-2257.

Zaitsev, A. V., Gonzalez-Burgos, G., Povysheva, N. V., Kroner, S., Lewis, D. A., and Krimer, L. S. (2005). Localization of calciumbinding proteins in physiologically and morphologically characterized interneurons of monkey 
dorsolateral prefrontal cortex. Cereb. Cortex 15, 1178-1186.

Zheng, P., Zhang, X. X., Bunney, B. S., and Shi, W. X. (1999). Opposite modulation of cortical N-methyl$\mathrm{D}$-aspartate receptor-mediated responses by low and high concentrations of dopamine. Neuroscience 91, 527-535.

Zhou, F. M., and Hablitz, J. J. (1999). Dopamine modulation of membrane and synaptic properties of interneurons in rat cerebral cortex. J. Neurophysiol. 81, 967-976.

Zhou, X., Katsuki, F., Qi, X. L., and Constantinidis, C. (2012). Neurons with inverted tuning during the delay periods of working memory tasks in the dorsal prefrontal and posterior parietal cortex. J. Neurophysiol. [Epub ahead of print].

Conflict of Interest Statement: The authors declare that the research was conducted in the absence of any commercial or financial relationships that could be construed as a potential conflict of interest.

Received: 29 February 2012; paper pending published: 27 March 2012; accepted: 16 April 2012; published online: 03 May 2012.

Citation: Katsuki $F$ and Constantinidis $C$ (2012) Unique and shared roles of the posterior parietal and dorsolateral prefrontal cortex in cognitive functions Front. Integr. Neurosci. 6:17. doi: 10.3389/fnint.2012.00017

Copyright (c) 2012 Katsuki and Constantinidis. This is an open-access article distributed under the terms of the Creative Commons Attribution Non Commercial License, which permits non-commercial use, distribution, and reproduction in other forums, provided the original authors and source are credited. 